\section{Bioethics in paediatric practice}

\author{
Pareshkumar Amrutlal Thakkar $^{1}$, Supriya Phanse ${ }^{2}$
}

Sri Lanka Journal of Child Health, 2012; 41(3): 109-113

(Key words: Bioethics; children)

\section{Introduction}

There have been increasing concerns about the ethical considerations in the care of children over the last few decades. Generally ethical reasoning was focused on issues surrounding adults with decisional capacity and the principle of respect for autonomy. However, and in contrast, paediatric medicine and ethics begin with more expansive views of patientprofessional interaction. Decisions about infants are projections of familial, medical and cultural values in the hope that these projections will either positively shape or allow for later development of the child's own interests and values ${ }^{1}$.

\section{Ethics}

The medical profession has been based on the basic principles 'primum non nocere' and 'voluntas aegroti suprema lex' ('first do no harm' and 'the will of the patient is the supreme law'), 'beneficence' ('do good'), 'nonmaleficence'('do no harm'), 'dignity', 'respect', 'autonomy', 'self-determination', 'justice' and 'fairness ${ }^{2,3}$.

\section{Ethics and informed consent}

The doctrine of informed consent reminds us to respect persons by fully and accurately providing information relevant to exercising their decisionmaking rights. The goals of this consent process include the development of the patient's comprehensive understanding of the clinical situation, and the timely exercise by the patient of active choices regarding the circumstances ${ }^{4,5}$. The patient should be afforded complete freedom to opt out without any subsequent untoward consequences.

${ }^{1}$ Assistant Professor of Paediatrics, Member Secretary of Institutional Ethics Committee, Medical College and SSG Hospital, Vadodara, Gujarat, ${ }^{2}$ Assistant Professor of Paediatrics, Medical College Jamnagar, Gujarat

\section{Problems with the concept of "consent by proxy"}

In attempting to adapt the concept of informed consent to paediatrics, many believe that the child's parents or guardians have the authority or "right" to give consent by proxy which usually works well as parents steadfastly guard the interests of their children. However, the concept of consent (literally "to feel or sense with") expresses something for one's self. A person who consents does so based on unique personal beliefs, values, and goals.

Thus "consent by proxy" may pose serious problems for paediatric health care providers. Such providers have legal and ethical duties to their child patients to render competent medical care based on what the patient needs and not what someone else expresses. Although impasses regarding the interests of minors and the expressed wishes of their parents or guardians are rare, the paediatrician's responsibilities to his or her patient exist independent of parental desires or proxy consent ${ }^{6}$.

The development of the child as person and the concept of assent

Decision-making involving the health care of older children and adolescents should include, to the greatest extent feasible, the assent of the patient as well as the participation of the parents and the physician $^{7,8}$. As children develop, they should gradually become the primary guardians of personal health and the primary partners in medical decisionmaking, transferring responsibility from their parents to themselves. Just as is the case with informed consent, the emphasis on obtaining assent should be on the interactive process in which information and values are shared and joint decisions are made. The development of new bureaucratic mechanisms, such as "assent forms", which could never substitute for the relational aspects of consent or assent, is not recommended. 


\section{The patient's refusal to assent (dissent)}

There are clinical situations in which a persistent refusal to assent (i.e. dissent) may be ethically binding 9 . This seems most obvious in the context of research, particularly those which have no potential to directly benefit the patient ${ }^{10}$. A patient's reluctance or refusal to assent should also carry considerable weight when the proposed intervention is not essential to his or her welfare and/or can be deferred without substantial risk.

Mechanisms to resolve ethical conflicts include additional medical consultation(s), short-term counselling or psychiatric consultation for patient and/or family, "case management" or similar multidisciplinary conference(s) and/or consultation with individuals trained in clinical ethics or a hospital-based ethics committee. In rare cases of refractory disagreement, formal legal adjudication may be necessary.

\section{Legal emancipation and informed consent}

The laws designate two settings in which minors have sole authority to make health care decisions ${ }^{11}$. First, certain minors are deemed "emancipated" and treated as adults for all purposes. They include those who are self-supporting and/or not living at home, married, pregnant or a parent, in the military or declared to be emancipated by a court of law. Second, many states give decision-making authority (without the need for parental involvement) to some minors who are otherwise un-emancipated but who have decision-making capacity ("mature minors") or who are seeking treatment for certain medical conditions such as sexually transmitted diseases, pregnancy and drug or alcohol abuse ${ }^{12}$.

\section{Ethics in paediatric clinical practice}

In cases involving the following kinds of medical care for infants and young children, the American Academy of Paediatrics (AAP) encourages physicians to seek the informed permission of the parents. These include providing immunizations, performing invasive diagnostic testing for a congenital cardiac defect, beginning long-term anticonvulsant therapy to control a seizure disorder, initiating serial casting to correct congenital "clubfoot" or undertaking surgical removal of a "suspicious" neck mass.

Even in pressing situations, informed permission should be sought for actions such as performing a lumbar puncture to evaluate the possibility of meningitis. Even if parents deny permission, treatment should be started immediately based on clinical judgment rather than delaying treatment or performing lumbar puncture without authorization.

For older school-age children, the Academy encourages physicians to seek the assent of the patient as well as the informed permission of the parents. In some cases, treatment may have to proceed irrespective of the objection of the patient. However, physicians and parents should realize that over-ruling the child may undermine their relationship(s) with the child.

Review of the limited relevant empirical data suggests that adolescents, especially those aged 14 and older, may have as well developed decisional skills as adults for making informed health care decisions ${ }^{13-15}$. Ethical and legal factors, (i.e. confidentiality and/or privacy), suggest that the physician needs to involve parents after appropriate discussion with the adolescent elicits his or her permission to do so. In some cases in which the patient has no legal entitlement to authorize treatment, the physician may have a legal obligation in some jurisdictions to obtain parental permission or in certain cases, to notify parents in addition to obtaining the patient's consent. An adolescent's refusal of consent in cases such as these may well be legally (and ethically) binding. If "conflict resolution" fails, formal, legal adjudication may be needed $^{8}$

\section{Ethical issues in resuscitation of newborns at the margins of viability}

The recent consensus in neonatal ethics states that the standard of care for newborns, who, unlike adults, are not able to formulate or articulate their personal values or preferences, should be in the realm of the "best interests of the infant", While the Harvard Medical School yields the decision to the parents even over and against physicians' objections that the decision in a particular case is "wrong", the Nuffield Council and the AAP take the position that newborns are to be treated as any other patient, on the basis of their best interests. This implies that although parents may and should continue to be involved in decision making for their children, they do not have the exclusive right to refuse, or demand, certain forms of medical treatment for the child ${ }^{17}$.

As per the AAP, the treatment decisions for a marginally viable newborn in the best interest can be divided into three categories: 
1. When early death is very likely and survival would be accompanied by a high risk of unacceptable severe morbidity, intensive care is not indicated.

2. When survival is likely and the risk of unacceptably severe morbidity is low, intensive care is indicated.

3. In the "grey area" where prognosis is uncertain but likely to be very poor and survival associated with a diminished quality of life, parental desires should determine the treatment approach ${ }^{18}$.

Data from a study conducted in the NICU at the University of Chicago between 1999 to 2008 to quantify the cost and predict futile care based on the duration of mechanical ventilation requirement showed that only $6 \%$ of NICU expenses were spent on non-survivors and thus futile. If only money spent after predictions of death was considered, futile expenses fell to $4.5 \%$. NICU care was preferentially directed to survivors for even the smallest infants, at the highest risk to die. Over $75 \%$ of ventilated NICU infants were correctly predicted to survive on every day of ventilation by every caretaker. However, predictions of 'death before discharge' were wrong more than one time in three. Thus criticisms of the expense of NICU care find little support in these data. Rather, NICU care is remarkably well targeted to patients who will survive, particularly when contrasted with care in adult ICUs. The need of the hour is to search for better prognostic tools for individual infants while continuing to give on-going care in the $\mathrm{NICU}^{19}$.

\section{Ethical issues in paediatric palliative care}

Paediatric palliative care is an active and total approach to care, embracing physical, emotional, social and spiritual elements. It focuses on the enhancement of quality of life for the child and support for the family and includes the management of distressing symptoms, provision of respite and care through disease, death and bereavement. Here comes the role of the principle of double effect by Thomas Aquinas. The principle explains the permissibility at producing a good effect, even if doing the action may lead to an unintended "bad" effect. Thus, while providing palliative care, opioids can be used to relieve distressing symptoms such as dyspnoea and pain in spite of unintended adverse effects such as respiratory depression. Today careproviders advocate provision of comfort with curative care and excellent pain relief. Families no longer have to choose between curative and palliative care, they can simultaneously have both, thus maximizing the child's quality of life ${ }^{3}$.

\section{Ethical issues in genetic testing and counselling}

Advances in genetic research promise great strides in the diagnosis and treatment of many childhood diseases. However, emerging genetic technology often enables testing and screening before the development of definitive treatment or preventive measures. In these circumstances, careful consideration must be given to testing and screening of children to ensure that use of this technology promotes the best interest of the child. It is recommended to promote informed participation by parents for newborn screening and limit the use of carrier testing and testing for late-onset conditions in the paediatric population. Additional research ventures and education in this developing area of medicine are encouraged ${ }^{20}$.

\section{Ethical issues in cases of intersex}

There are four critical limitations in our capacity to manage intersexuality clinically. First, it appears impossible to draw any bright line that decisively and non-arbitrarily separates men and women. Second, even if there was such a procedure, parents lack the ability to engineer the psycho-social development of a target gender ${ }^{21}$. Third, we are unable to predict with confidence the gender that an intersexual newborn will settle into during adulthood. Indeed, we are often mistaken enough, even with anatomically typical infants. Finally, given the deep and largely uncharted pervasiveness of the effects of being a typical male or female, it is unlikely that surgical reassignment will ever truly "normalize."

It has been standard paediatric practice to recommend surgery for infants with ambiguous genitalia or loss of the penis. The parents of these patients are told to raise them without ambiguity and, in consequence, many adults who have had these operations in infancy have never been candidly informed of their medical histories. This management approach, which can involve a reassignment of sex, has its basis in research done on hermaphrodites and a single set of identical twins originally tracked more than two decades ago. It is argued that there should be a moratorium on such surgery, that the medical profession should complete comprehensive look-back studies to assess the outcomes of past interventions and that efforts should be made to undo the effects of past deception $^{22}$. 


\section{Conclusion}

The discipline of paediatric ethics is growing up. The very foundations of bioethics are different when questions arise in the medical care of children. Signs everywhere indicate that this difference is now being recognized. Perhaps the lack of clear solutions to many cases in paediatric practice demonstrates that the best approaches to issues of medical ethics can be debatable. Sometimes, there is no single "right" or "wrong" answer. Paediatric ethics programmes and centres are being established, national meetings are taking place, research in paediatric ethics is being funded and books are being published on the subject. These herald the beginning of a new era of paediatric practice which will strike a balance between evidence based medicine and ethical practice.

\section{References}

1. Hester M. Paediatric ethics - Why it deserves special attention. Practical Bioethics 2008; 3(4):1-5.

2. Thomas Aquinas. D.1274. Summa theologica IIII.q.64a.7.

3. Friedrichsdorf S, Osenga K. Principle of double effect in paediatric palliative care - pain management for seriously ill infants and child. Practical Bioethics 2008; 3(4):3.

4. Lidz CW, Appelbaum PS, Meisel A. Two models of implementing informed consent. Archives of Internal Medicine 1988; 148: 1385-9.

http://dx.doi.org/10.1001/archinte.1988.00380060149 $\underline{027}$

5. President's Commission for the Study of Ethical Problems in Medicine and Biomedical Research and Behavioural Research. Making Health Care Decisions: A report on the ethical and legal implications of informed consent on the patientpractitioner relationship. Washington, DC: US Government Printing Office; 1982: Vol 1.

6. Weir RF. Selective non-treatment of handicapped newborns: Moral dilemmas in neonatal medicine. New York, NY: Oxford University Press; 1984.

7. King NMP, Cross AW. Children as decision makers: guidelines for paediatricians. Journal of Pediatrics 1989; 115:10-16. http://dx.doi.org/10.1016/S0022-3476(89)80321-X
8. Committee on Bioethics. Informed consent, parental permission, and assent in paediatric practice. Pediatrics 1995; 95(2):314-7.

9. Leikin S. Minors' assent or dissent to medical treatment. Journal of Pediatrics 1983; 102:169-76. http://dx.doi.org/10.1016/S0022-3476(83)80514-9

10. Leikin S. Minors' assent, consent, or dissent to medical research. Institutional Review Board 1993; 15:1-7.

11. Holder AR. Legal issues in paediatrics and adolescent medicine. 2nd ed. New Haven, CT: Yale University Press; 1985.

12. Sigman GS, O'Connor C. Exploration for physicians of the mature minor doctrine. Journal of Pediatrics 1991; 119:520-5. http://dx.doi.org/10.1016/S0022-3476(05)82398-4

13. Brock DW. Children's competence for health care decision-making. In: Kopelman LM, Moskop JC, eds. Children and Health Care: Moral and Social Issues. Boston, MA: Kluwer Academic Publishers; 1989:181-212.

http://dx.doi.org/10.1007/978-0-585-27406-5_16

14. Lewis CE, Lewis MA, Ifekwunigue M. Informed consent by children and participation in an influenza vaccine trial. American Journal of Public Health 1978; 68:1079-82.

http://dx.doi.org/10.2105/AJPH.68.11.1079

15. Weithorn LA, Campbell SB. The competency of children and adolescents to make informed treatment decisions. Child Development 1982; 53:1589-98. http://dx.doi.org/10.2307/1130087

16. Paris J, Ferranti J, Reardon F. From the John Hopkins Baby to Baby Miller: What we have learned from four decades of reflection on neonatal cases. Journal of Clinical Ethics 2001; 12(3):207-14.

17. Nuffeld Council on Bioethics 2006. Critical care decisions in fetal and neonatal medicine: Ethical Issues. Available from:

www.nuffeldbioethics.org/go/ourwork/neonatal/publi cation_406.html. Accessed 12/04/07.

18. American Academy of Paediatrics Committee on Fetus and Newborn. Non-initiation or withdrawal of intensive care for high-risk newborns. Pediatrics 2007; 119:401-3. http://dx.doi.org/10.1542/peds.2006-3180 
19. Meadow W, Cohen-Cutler S, Spelke B, Kim A, Plesac M, Weis K, Lagatta J. The prediction and cost of futility in the NICU. Acta Paediatrica 2012; 101(4): $397-402$.

http://dx.doi.org/10.1111/j.1651-2227.2011.02555.x

20. Committee on Bioethics, AAP. Ethical issues with genetic testing in paediatrics. Pediatrics 2001; 107(6): 1451-5.

http://dx.doi.org/10.1542/peds.107.6.1451

21. J.R. Harris. The Nurture Assumption, New York: The Free Press, 1998.

22. Kipnis K, Diamond M. Paediatric ethics and the surgical assignment of sex. The Journal of Clinical Ethics 1998; 9 (4):398-410.

\section{SLMA SNAKEBITE HOTLINE}

Faced with a snakebite management dilemma? Now you can seek expert advice, day or night. Call one of the following:

For adult snakebite victims

Prof. S. A. M. Kularatne: 0812-388369 or 0773-420771

Dr. M. K. Ragunathan: 0777-904500 or 0718-166599

Prof. Ariaranee Gnanathasan: 0112-508200, 0112-364088 or 0773-279659

Dr. Suresh Mendis: 0773420491

For snakebites in the Jaffna District, especially saw-scaled viper bites

Dr. S. Sivansuthan: 0777916231

For paediatric snakebite victims

Dr. Udaya de Silva: 0718-607697

SLMA Expert Committee on Snakebite

August, 2012 